\title{
Review of Development Stages in the Conceptual Design of an Electro-Hydrostatic Actuator for Robotics
}

\author{
Velibor Karanović, Mitar Jocanović \\ University of Novi Sad \\ Faculty of Technical Sciences \\ Trg Dositeja Obradovića 6, 21000 Novi Sad, Serbia \\ e-mail: velja_82@uns.ac.rs; mitarj@uns.ac.rs
}

\author{
Vukica Jovanović \\ Old Dominion University \\ Mechanical Engineering Technology \\ 111-D Kaufman Hall \\ Norfolk, VA 23529, USA \\ e-mail: v2jovano@odu.edu
}

\begin{abstract}
The design of modern robotic devices faces numerous requirements and limitations which are related to optimization and robustness. Consequently, these stringent requirements have caused improvements in many engineering areas and lead to development of new optimization methods which better handle new complex products designed for application in industrial robots. One of the newly developed methods used in industrial robotics is the concept of a self-contained power device, an Electro-Hydrostatic Actuator (EHA). EHA devices were designed with a central idea, to avoid the possible drawbacks which were present in other types of actuators that are currently used in robotic systems. This paper is a review of the development phases of an EHA device for robotic applications. An overview of the advantages and disadvantages related to current EHA designs are presented, and finally possible ideas for future developments are suggested.
\end{abstract}

Keywords: electro-hydrostatic actuator; hydraulics; robotics

\section{Introduction}

As a scientific area, robotics and its application have achieved a very high level of development and are present in almost all human activities. The intention of mankind, to assign precise, heavy and dangerous routine and non-routine jobs to 
machines, has prompted the development of science and engineering, robotics included [1-6]. Application of robotics has allowed accurate, precise and highly efficient performance of such work tasks, with or without human interference.

With the aim of performing the designated tasks with utmost efficiency, robotic applications should have following characteristics: functional design, optimized control unit and adequate power drive unit (an aggregate). Functional design pertains to design solutions which allow simple robot control for the most efficient realization of tasks (functions). Control units should provide reliable, adjustable and efficient control of a robot in any situation. Finally, power a drive unit, using one or a combination of energy sources (electric, pneumatic, and hydraulic), is tailored to match the given task and operating conditions. In order to achieve maximum working performance and avoid drawbacks of classical drive units, various authors have contributed to research and development of combined robotic drive units [7-13]. One such example is the development of the combined electro-hydrostatic drive (EHA - Electro-Hydrostatic Actuator).

As a self-contained power device [14] the Electro-Hydraulic/Hydrostatic Actuator (EHA), was first developed and patented in 1950s to actuate landing gears, wing flaps or other movable parts of an aircraft. Generally, the EHA device was designed to suit applications in which smaller size and weight-to-power ratio are required (for example hand and leg prosthesis, exoskeletons, etc.). Considering the advantages and drawbacks of EHA, scientists and engineers have subsequently investigated various possibilities to adapt EHA for different applications.

The goal of this paper is to present an overview of those research papers which deal with the application of combined electro-hydrostatic actuators in robotics. The combination of various drive types is aimed towards achieving the best possible task performance, as well as some other benefits which are difficult to attain using conventional drives. The second section of this paper provides an overview of important contributions in this area. In the third section presents a critical review of the advantages and disadvantages of EHA devices previously discussed in the paper and in the last chapter, the conclusions and possibilities of further development of EHA units are discussed.

\section{A Review of EHA Development}

Design problems related to current drive systems in robotics are very frequently a research focus in the advancement of energy consumption efficiency. Hydraulic drives are usually used in a robust robotic applications which perform tasks under heavy workloads. However, thanks to the improvements in advanced manufacturing technology, the use of hydraulic drives in miniature robotic systems is increasing. These new, miniaturized solutions are developed for the purpose of maximum efficiency and better exploitation of available resources (materials, size, energy, etc.). 
Power-by-Wire technology was developed for aerospace industry [15] and further refined and improved to adapt EHA devices for industrial applications in robotics. The integration of hydraulic components which work with electrical components that control the hydraulic system, resulted in a number of advantages. Some of these were related to improved flexibility during operation, decreased energy use, smaller size, higher power-to-mass ratio and improved continuous control of operating parameters under high external payloads. Significant technological advances in manufacture of hydraulic components along with improved integration of embedded systems, lead to new applications of hydraulics in robotics. New materials and new manufacturing technologies allowed manufacture of miniature hydraulic components, thus saving space and decreasing loads on the structure, while designed to sustain large enough forces to perform tasks. Beside their tighter tolerances, the miniature components also had a minimum oil leakage, provided that assembly was well completed and that maintenance was timely.

Hydraulic system designs, similar to EHA, are used in large and massive robots. One such application is the vehicle with adaptive suspension [16-18], which is the result of a military scientific project conducted at the University of Ohio during the eighties of the twentieth century. Some time later, Bobrow published his paper on the development of a hydraulic drive for robotic applications [19]. The paper was an attempt to solve the problem which occurs when trying to control high torques using a combination of electric motor and gear train transmission. This problem was basically caused by friction and backlash [20] (due to present clearance between meshed teeth), which is inherent to gear transmission. In case when gear train transmission is not present, the torque has to be controlled directly by electric motor, with high accuracy. However, high torques are not possible without the use of electric motors and power amplifiers (which leads to an increased overall dimensions and higher mass) [19]. Moreover, electric motors and power amplifiers have unstable efficiency rates in case of short bursts of maximum electric motor power. The mentioned friction between gear teeth causes not only energy losses, but also material wear. The material wear further causes changes in component geometry which has influence on gap increase, decreasing the positioning accuracy and precision.

According to Pastrakuljić [21], power transmission in a hydrostatic system can be realized in two ways: by using distribution valves or a variable displacement pump. Control by distribution valves is often used in industry but has limited flexibility. Pastrakuljić also points out drawback while using single and doubleacting cylinders. The difference in piston surface areas which are under pressure, results in the difference in piston rod forces and extension or retraction speeds. This problem can be partially solved using a differential distribution valve, whose ratio between the cross section areas of branches is proportional to the cross section areas ratio of piston with the single-action piston rod [21]. However, differential distribution valve solves the problem of piston rod extension or 
retraction speed, but has no effect on the force. This can be remedied using a double piston cylinder, bearing in mind that this solution is not always applicable due to spatial restrictions. Another type of power transmission control in a hydrostatic system is based on a pump which performs two roles: generates flow and controls operation of a hydraulic cylinder or motor. This principle lies behind the EHA concept. Simplified, EHA system represents a closed hydraulic circuit where the pump is directly connected with the hydraulic cylinder or motor. Within such concept, actuator can be controlled in several ways. Fig. 1a) shows the most simple type of closed hydrostatic circuit with the installed pump and hydraulic motor of constant displacement, with no control of work speed. Figure 1b) shows a system with variable displacement hydraulic motor. Therefore, it allows control of work speed by varying the displacement of hydraulic motor work chambers which is performed by a mechanism installed within the hydraulic motor. Illustrated in Fig. 1c) is the case which is most frequently used in practice - it features a variable displacement pump and a constant displacement hydraulic motor. Fig. 1d) illustrates a system with variable displacement pump and hydraulic motor, which provides optimal system adjustment with minimum losses. However, the system is very complex to control and therefore rarely used in practice.

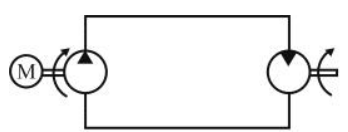

a)

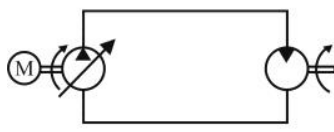

c)

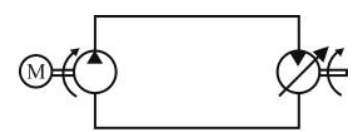

b)

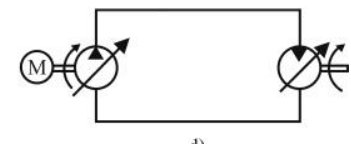

d)

Figure 1

Types of hydraulic power transmission in a closed circuit [21]

An EHA design is based on a closed hydraulic circuit with a built-in bidirectional variable-displacement hydraulic pump, powered by an electric motor, and a bidirectional constant-displacement hydraulic actuator (cylinder or motor). There are two ways to control the pump displacement. The first, standard way of control, is to use the pump capable of regulating the volume of work chambers (servo pump), such as the axial piston pump with the swash-plate or vane pump and radial piston pump with variable eccentricity (distance between rotor and stator axes). Another way to control pump displacement is to adjust the number of revolutions using drive electric motor (servo motor) [15] (Fig. 2).

Linear, electrically actuated pump control was used in laboratory tests of EHA device, performed by Pastrakuljić [21], Habibi and Goldenberg [22, 23] (Fig. 3). The downside of such approach to control is the dead-band which occurs during the inversion of electric motor rotation [22]. 


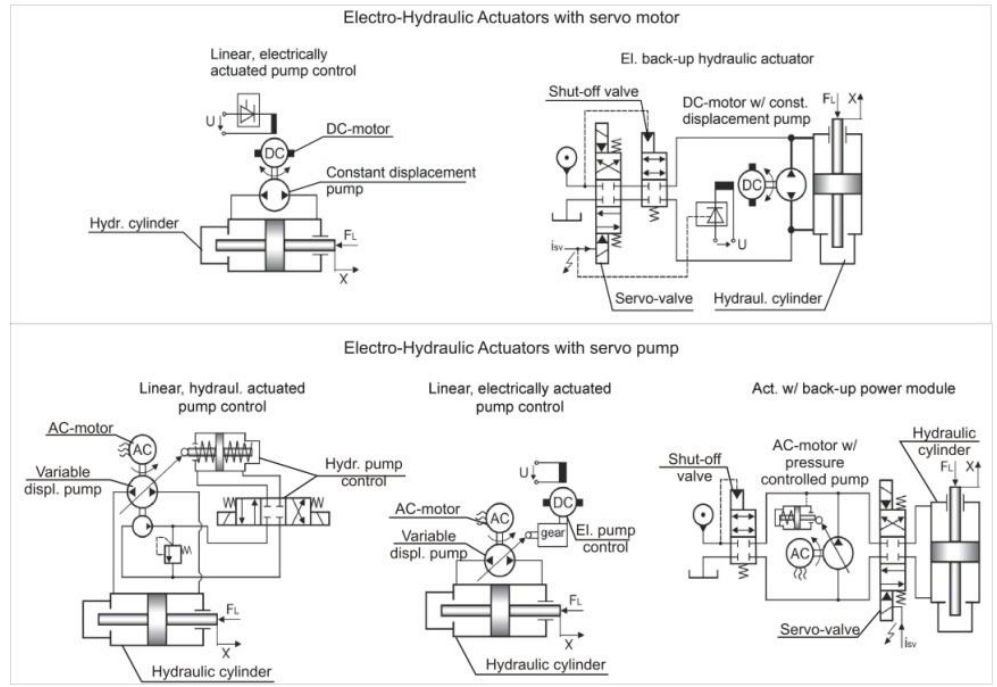

Figure 2

Control configuration of EHA system [15]

The dead-band represents magnitude of voltage or current values, for which the electric motor gives no response, and can be compared to backlash of gear transmission. In order to alleviate this effect, an adequate electric motor control system has been developed. For use in EHA system, Habibi proposes a gear pump which, compared to piston pumps, provides a more even flow at the discharge duct.

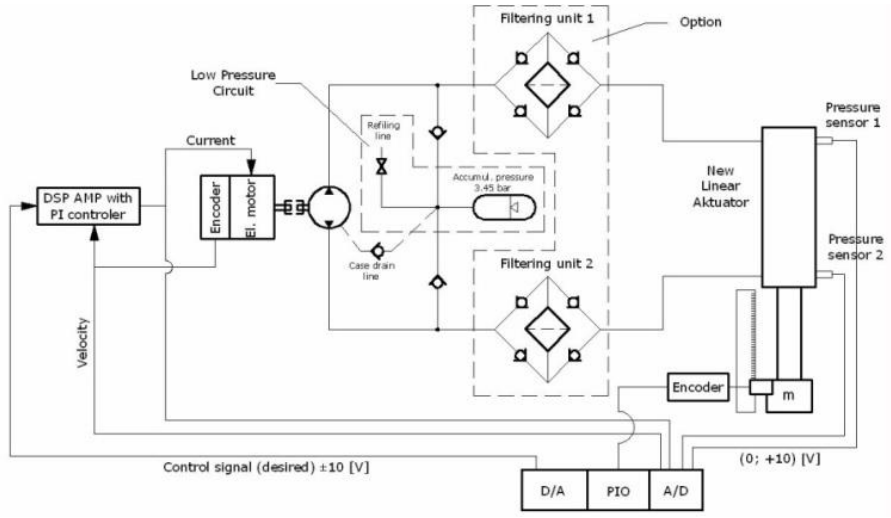

Figure 3

Scheme of EHA system [21]

Contribution to the development of EHA concept design for robots, has been made by Alfayad et al. [24-26]. His proposal is an answer to the already mentioned basic drawbacks of electromechanical, and also hydraulic drives. $\mathrm{He}$ 
points out the drawback which pertains to the lack of centralized supply of hydraulic energy. An example of centralized energy supply is CB (Computational Brain) humanoid robot [27] or Big Dog, the quadruped robot developed by Boston Dynamics [28]. The basic flaw of the centralized system is that it has to satisfy the maximum load requirements of all the hydraulic actuators installed in a robot. Even with optimized design solutions of centralized hydraulic aggregates it often happens that their overall dimensions and mass are significant. It should be noted that control valves for hydraulic actuators also contribute to the increase of mass and overall dimensions of design solution. Bearing in mind that the actuators are located in robot joints - where they provide required element movements - it is necessary to connect them to the central aggregate by pipe line and/or hose line. This, in turn, increases the chances of hydraulic losses due to oil leaks or oil flow through the pipe line/hose line and the connectors. These unwanted effects are further exacerbated when using hydraulic hoses which run through the joints to connect actuators with the aggregate [25]. However, their use is required if the actuator is at some distance from power unit, and fixed to the element which performs movement during robot operation. The discussed flaws have prompted the research and development of the novel Integrated Electro-Hydraulic Actuator (IEHA) $[25,26]$. The idea behind IEHA concept is based on two fundamental requirements. The first is to integrate hydraulic components (pump, reservoir, electric motor, pressure and position sensors) into a device which occupies small space and have bigger ratio power to weight, while the other is to simplify device control.

It has always been the problem to integrate robust and massive hydraulic components into sophisticated devices of miniature dimensions. Of course, such task can be realized at a high price. Nowadays, thanks to high technological development, miniature hydraulic components are a part of standard offer on the market, which has significantly reduced component prices. Thus, hydraulic components and systems are becoming attractive and are increasingly studied and researched within the area of robotics.

Small-space integration of IEHA components represents the realization of the decentralization principle. Owing to decentralization, each joint has its own IEHA installed, becoming an autonomous unit controlled by a centralized control system. The advantage is in avoiding the use of pipe lines and hose line to connect actuators and the aggregate which cancels the leak losses due to flow of work fluid through pipes/hoses. Also worth noting is the fact that each IEHA is sized according to host joint requirements. This significantly increases the aggregate efficiency rate of the system.

Another important characteristic of the IEHA concept is the simplified control process. In contrast to Habibi, Alfayad et al. propose pump displacement control by means of a mechanical-hydraulic regulation components built into the pump [24]. Evidently, the pump design must be adjusted to accommodate regulation components. This significantly simplifies the control of electrical motor drive, 
considering that the rotor maintains constant number of revolutions. In the discussed case, a radial piston pump was used which - using certain (fixed) values of eccentricity - achieved flow and output pressure whose relation is shown on the diagram (Fig. 4).

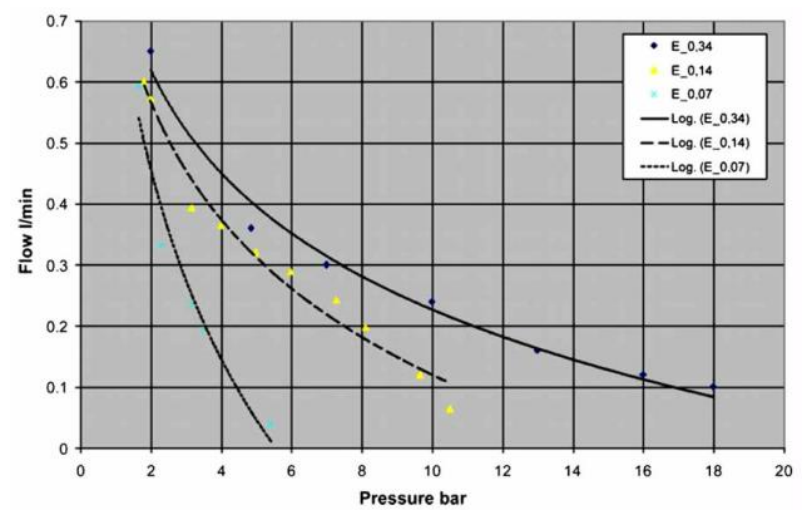

Figure 4

Relation of output flow and pressure values of IEHA for three eccentricity values $(E=0.34 ; 0.14 ; 0.07$ mm) [25]

Experimental test of IEHA includes the lifting of 25 and $38 \mathrm{~kg}$ weights at 20 $\mathrm{mm} / \mathrm{s}$, where the cylinder piston is $20 \mathrm{~mm}$ in diameter and length of the piston rod is $120 \mathrm{~mm}$. The same speed was obtained with both tests [25]. These results show potential capabilities of IEHA in terms of power-to-mass, and power-to-volume ratio. The specifications and real parameters of the manufactured IEHA prototype are given in Table 1 .

Table 1

IEHA specifications [24]

\begin{tabular}{|l|l|c|}
\hline \multicolumn{1}{|c|}{ Parameter } & \multicolumn{1}{c|}{ Value } & Unit \\
\hline Size LxWxP & $80 \times 40 \times 40$ & $\mathrm{~mm}$ \\
\hline Weight & 1000 & $\mathrm{~g}$ \\
\hline Eccentricity & \pm 0.5 & $\mathrm{~mm}$ \\
\hline Number of pistons $(\mathrm{N})$ & 20 & - \\
\hline Rotation speed $(\omega)$ & 3000 & $\mathrm{RPM}$ \\
\hline Piston radius $\left(\mathrm{R}_{\mathrm{p}}\right)$ & 1.5 & $\mathrm{~mm}$ \\
\hline Flow $(\mathrm{Q})$ & \pm 500 & $\mathrm{~cm}^{3} / \mathrm{min}$ \\
\hline Pressure $(\mathrm{P})$ & $50-100$ & $\mathrm{bar}$ \\
\hline
\end{tabular}

In order to advance robot interaction with humans and environment, Kargov et al. designed a robotic hand prosthesis with hydraulic drive [29, 30]. Although based on the use of a centralized hydraulic system, their investigation emphasizes the need to miniaturize hydraulic components and points out their efficiency (Fig. 5). 
In this paper, miniature components were made, enabling the hydraulic system consisting of the pump, reservoir, control valves, electric motor drive and control unit - to be built into the natural-size robotic hand prosthesis. Moreover, its compact size and functionality allowed maximum performance.

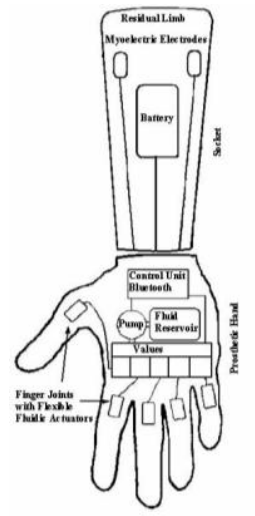

a)

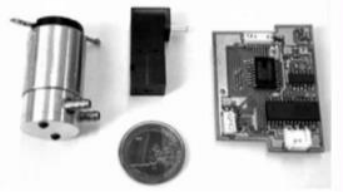

b)

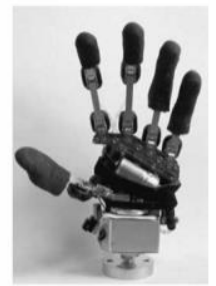

c)

Figure 5

a) Schematic view of Kargov prosthetic hand; b) Size comparison of hydraulic pump (left); microvalve (middle) and microcontroller (right) with a coin; c) Look of prosthetic hand [30]

Parallel to Kargov's work, Kaminaga et al. experimented with the application of electro-hydrostatic actuator on knee-joints and a robotic hand for a humanoid robot $[31,32]$. The goal of this investigation was to achieve certain degree of adaptability of the mechanisms which generate robot movements, in situations when the robot interacts with humans or objects within its environment. In order to achieve the desired degree of adaptability, which allow the robot to simulate human-like reactions, when facing an obstacle. The built-in mechanisms generate human movements, with a convenient degree of back-drivability. Failing this requirement is liable to cause errors such as the displacement or breakage of the encountered object (obstacle), damage to the robot, positioning error, etc. The very ability of back-drivability gives the advantage to hydrostatic systems compared to their electric counterparts, since they are able to control the direction, sense and speed of movement under significant payloads. In confirmation of this claim, Fig. 6, shows a comparison between electro- and hydrostatic systems, relating their reaction speed, i.e., achievement of power unit per time unit. Additionally, the reliability of EHA device could be improved by use of vibrotactile force feedback strategy [33].

Beside the back-drivability, the paper [31] also points out the principle of modularity which facilitates assembly and disassembly of the system, thus improving maintenance. 

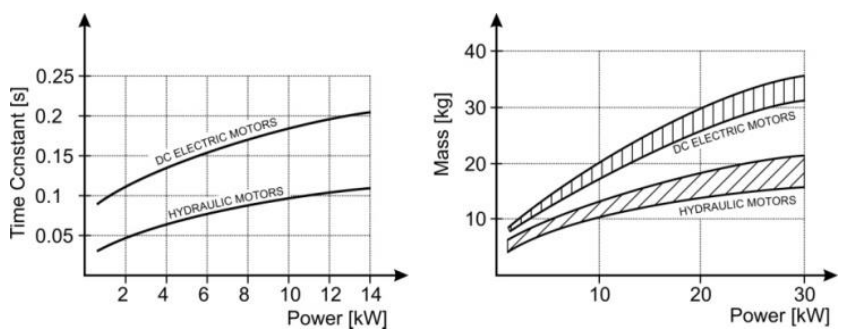

Figure 6

Time/Power and Mass/Power relationship for electrical and hydraulic motors [34]

Beside the back-drivability, the paper [31] also points out the principle of modularity which facilitates assembly and disassembly of the system, thus improving maintenance. Specially emphasized, as the advantage of hydraulic systems, is the fact, that a pressure increase leads to size reduction of hydraulic components, thus, contributing to diminished mass of the overall robot design. However, for the design solution proposed in this paper, pressure increase is limited due to use of hydraulic hoses. Hydraulic hoses are a flexible connection and are used to provide mobility of the hydraulic motor. At the same time, hydraulic hoses are a drawback for two primary reasons. Firstly, they are not fixed and are therefore potential obstacle to the movable elements during robot operation, and secondly, due to work pressure fluctuations, they are susceptible to breakage, which results in fluid leakage and pressure drop. Shown in Fig. 7, is a scheme of hydraulic system used to motorize robotic hand designed by Kaminaga. The hydraulic system of the anthropomorphic robotic hand is fairly simple. It is a closed hydraulic circle, which consists of a bidirectional trochoidal pump and constant displacement vane motors, one for each finger. To prevent oil deficiency and pump cavitations, due to leakage in components, additional oil supply is provided by the charge (or fill-in) pump.

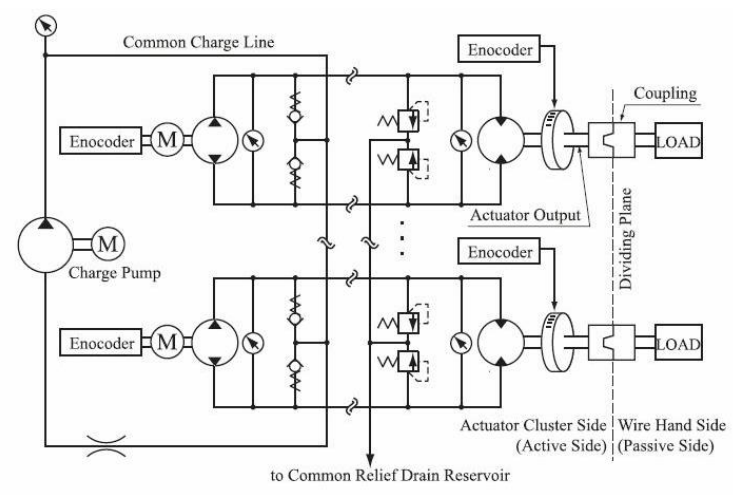

Figure 7

Anthropomorphic hand hydraulic scheme [31] 
In addition to pumps and motors, each closed hydraulic circuit has two pressure limiting valves (security valves). These valves react to unexpected work load (pressure) spikes in the discharge duct, which occur, for example, when a robot confronts an obstacle. According to practical experience, the pressure limiting valves are set to the value $10 \%$ higher than the maximum work pressure. Actuators' work speeds are controlled by a pump regulator device or drive electric motor whose direction and speed of rotation are adjusted to the pre-set and measured values of pressure, force and speed.

The similar design of electro-hydrostatic actuator, as shown in Fig. 7, was used for the knee power augmenting [35-37] to improve physical strength of a human, requiring less skills for effective operation (Fig. 8).

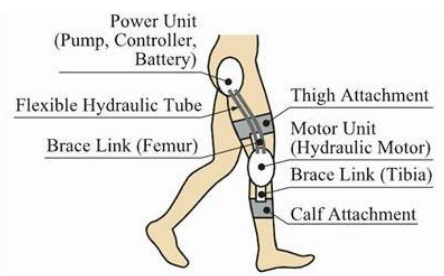

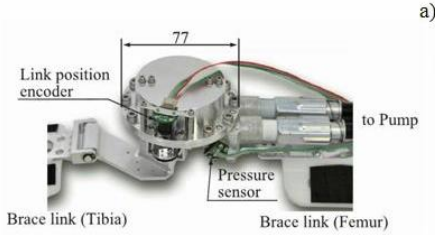

b)

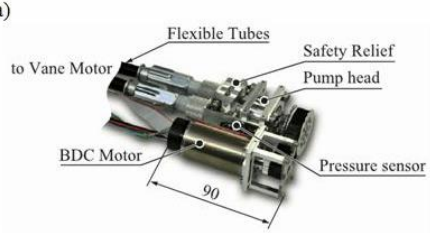

c)

Figure 8

a) Knee power assist with EHA; b) Hydraulic motor; c) Hydraulic pump unit [35]

To decrease weight of device, instead of charge pump, in this installation was used pressurized accumulator to prevent oil deficiency and pump cavitation. Also in [36] was proposed use of developed low- impedance controller, which combines inertia scaling and disturbance observer based friction compensation. The controller have a task to compensate pump friction or pressure loss due to fluid friction that occurs in hoses. Specifications for actuator used in [35-37] are given in Table 2.

Table 2

EHA specifications [35]

\begin{tabular}{|l|l|c|}
\hline \multicolumn{1}{|c|}{ Parameter } & \multicolumn{1}{c|}{ Value } & Unit \\
\hline Oil viscosity & 100 & $\mathrm{cSt}$ \\
\hline Weight & 1124 & $\mathrm{~g}$ \\
\hline Pump displacement & 0.36 & $\mathrm{~cm}^{3} / \mathrm{min}$ \\
\hline Motor displacement & 24 & $\mathrm{~cm}^{3} / \mathrm{min}$ \\
\hline
\end{tabular}




\begin{tabular}{|l|l|c|}
\hline Maximum speed of motor $(\omega)$ & 55 & RPM \\
\hline Maximum torque of motor $(\mathrm{M})$ & 30 at $10 \mathrm{rpm}$ & $\mathrm{Nm}$ \\
\hline Maximum operating pressure $(\mathrm{p})$ & 46 & bar \\
\hline
\end{tabular}

Testing results of the power augmenting device show that the energy consumption of operator was reduced by $25 \%$ [36].

To improve back-drivability of an EHA and reduction of friction between sliding mechanical components of the pump, Kaminaga [38, 39] proposed use of viscous screw pump (Fig. 9), that transfers mechanical kinetic energy to fluid kinetic energy with viscous friction of the fluid. Screw pumps have some advantages over gear, vane and piston pumps such as small friction, high speed operation and very small pressure and flow pulsations. This is important in order to achieve smooth force control.

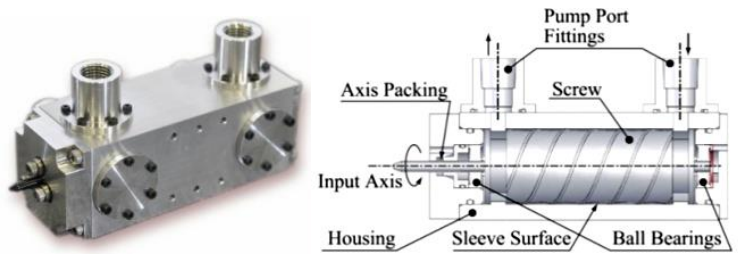

Figure 9

Outlook and cross section of developed screw pump design [38]

Evaluation of the developed screw pump performance is shown in Fig. 10. Linearity is present between the flow rate and pressure changes for each applied torque.

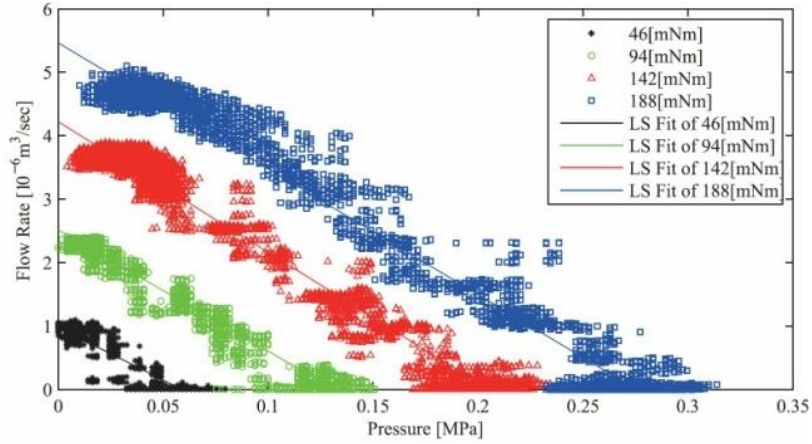

Figure 10

Result of pressure-flow rate characteristics evaluation. LS fit shows the lines fit with least-square method [38]

The presented mechanical design of the screw pump prototype achieved maximum discharge pressure of 12 bar and maximum flow rate of $3 \mathrm{~cm}^{3} / \mathrm{min}$. Also, the screw pump achieved $30 \%$ reduction of the pulsation against the trochoid pump in the worst case, while the total back-driving torque was one third 
that of the case with the trochoid pump, which significantly improved efficacy and back-drivability of EHA. Design parameters of the screw pump are shown in Table 3.

Table 3

Screw pump specifications [38]

\begin{tabular}{|l|l|c|}
\hline \multicolumn{1}{|c|}{ Parameter } & \multicolumn{1}{c|}{ Value } & Unit \\
\hline Oil viscosity & 100 & $\mathrm{cSt}$ \\
\hline Axial screw length $\left(\mathrm{l}_{\mathrm{t}}\right)$ & 62 & $\mathrm{~mm}$ \\
\hline Bore diameter $\left(\mathrm{d}_{\mathrm{t}}\right)$ & 28 & $\mathrm{~mm}$ \\
\hline Groove width $\left(\mathrm{w}_{\mathrm{c}}\right)$ & 9 & $\mathrm{~mm}$ \\
\hline Groove depth $\left(\mathrm{h}_{\mathrm{c}}\right)$ & 0.5 & $\mathrm{~mm}$ \\
\hline Ridge width $\left(\mathrm{w}_{\mathrm{b}}\right)$ & 1 & $\mathrm{~mm}$ \\
\hline Screw-sleeve gap $\left(\mathrm{h}_{\mathrm{g}}\right)$ & 15 & $\mu \mathrm{m}$ \\
\hline Number of helices $\left(\mathrm{n}_{\mathrm{t}}\right)$ & 3 & - \\
\hline Reduction before pump & 2 & - \\
\hline
\end{tabular}

Authors of this paper think that, implementation of condition monitoring in hydraulic systems, such as EHA/IEHA for robotics can significantly increase reliability and safety, and decrease maintenance costs. As the result of his investigation, Chinnah [40] developed an approach to monitoring relevant parameters using extended Kalman filter in order to increase reliability and efficiency of EHA devices. More precisely, he monitored two important parameters - bulk modulus and viscosity modulus, and their influence on EHA performance. The reduction of effective bulk modulus, as the result of the air in work fluid, significantly affects the response speed of EHA device, which reduces its stability in operation. On the other hand, the change in viscosity modulus indicates fluid contamination, sealant wear and/or wear of functional surfaces on components, which also impacts EHA operating efficiency. Sampson [41] also contributed to the development and improvement of EHA robot devices by investigating the possibility to achieve high positioning accuracy, which is measured on a nano scale. He employed fuzzy logic to provide control of positioning accuracy regardless of the magnitude of work forces and lengths of working strokes, taking into consideration Coulomb friction. The EHA control model was also advanced by contribution of Lin [42], who worked on the development of a controller which considers both the influence of friction and other non-linear parameters.

\section{Advantages and disadvantages of EHA/IEHA units}

From the presented research, summarized in this literature review, it is evident that researchers have put significant effort into investigation and development of novel actuator devices in robotic systems. A focus was placed on analysis of 
previous research related to the development of a hybrid solution of actuator which yields high operating performance and meets numerous requirements of robotic systems users from various domains - robotic prosthesis for human limbs, humanoid robots, military applications, etc.

Although electric motors are reliable, compact and controllable, they suffer from deficiencies which render them incomplete despite the fact that they are the most frequently used actuators for robotic applications. Owing to their favorable features, hybrid (combined) electro-hydrostatic actuators can compensate for those deficiencies. Application of EHA/IEHA eliminate two important deficiencies: backlash (which are the result of tolerances of nominal dimensions and in-service wear of components used for power transmission - gear trains) and the small power-to-mass ratio.

EHA/IEHA unifies a number of characteristics which meet requirements of modern robotic systems. According to laboratory tests reported by previously mentioned authors, EHA/IEHA successfully meets requirements such as: accuracy, precision, simple control, ability to integrate, modularity, flexibility, compactness, energy efficiency, small mass, continuous control of rotation direction under high payloads, etc.

The concept of EHA/IEHA application requires that every joint or movable component has its own self-contained drive unit, which allows its independent operation even in case when some of the joints' drives fail (according to the principle of decentralization). This is not achievable with the centralized hydraulic aggregate, where, in case of its failure, the hydraulic system is out of service. Decentralization principle is also beneficial to maintenance. It is simpler and faster to replace a compact device installed within a joint, than to replace a complete central aggregate. One of the main drawbacks of the conventional hydraulic systems is that they rely on the central hydraulic aggregate. The central aggregate consists of one or more hydraulic pumps, which are actuated by one or several electric motors (or internal combustion engine, in case of a mobile application), and a spacious reservoir filled with hydraulic oil. The pump, electric motor and reservoir must be sized to meet requirements of all the actuators installed within robotic application. On the down side, this contributes to increase of robot design overall dimensions and mass.

The drawback of hydraulics, mentioned in reference [22], is variable pressure, which significantly affects accuracy and precision of robot operation. In addition to positioning accuracy, this phenomenon can affect the durability of individual components, e.g., hydraulic hoses. Pressure oscillations can lead to premature failure of hydraulic hoses. Such fluctuations can never be entirely eliminated, but certain contemporary solutions can greatly alleviate the problem. Available solutions include application of accumulator, Helmholz resonator, adaptive hydropneumatic pulsation damper, etc. [43-45]. 
One of the often considered drawbacks related to hydraulic components, are the internal and external fluid leaks. Internal fluid leak means oil flow from high- to low pressure zone (within components), while the external leak occurs outside the system, into environment. Increased presence of leaks affects total efficiency rate of individual hydraulic components, and the entire system. Hydraulic oil leaks increase either due to increase of the clearance between component work elements, or due to lower viscosity of hydraulic oil. Although modern seals are made of advanced materials - while the tolerances are ever tighter, either as the result of miniature hydraulic components, or increased accuracy and precision friction is always present during operation as the result of the wear of contact surfaces. This increases clearances, and promotes oil leaks. The wear process, resulting in energy dissipation, depends on operating conditions, contact pairs materials, level of oil contamination, etc., but is certainly smaller than that in a case of mechanical transmission (gear train, friction pairs, levers, etc.).

An important detail also worth noting, in the authors' opinion, is that IEHA system [25] lacks a pressure limiting valve. The pressure limiting valve protects the system from overstepping the maximum allowed work pressure. Instead of pressure limiting valve, the system is equipped with sensors which define its operation, react to external influences, sending signals to control unit which decreases or increases pump capacity (indirectly regulating the pressure) by regulating eccentricity. This means that, when a disturbance in system operation occurs, the sensors should register pressure increase, and adequately regulate pump operation. Therefore, pressure increase and its regulation depend on the operation of sensors, central control unit, and pump. This is questionable in terms of control reliability, since it depends on more components than the solution which relies on the pressure limiting valve which directly regulates emerging disturbances.

The micro-pump for IEHA has complex design, especially if manufacturing tolerances are very tight, nearing those of the servo and proportional components (from 1 to $5 \mu \mathrm{m}$ ), which requires high quality surface finish and increases manufacturing costs. Complex design and high quality surface finish demand greater attention to component maintenance in general, with primary focus on the maintenance and conditioning of the energy medium, i.e., work fluid. Due to fluid contamination with particles, different wear mechanisms occur which most often contribute to failures of hydraulic systems. It is important to note that, due to the wear, system components become an internal source of fluid contamination. This contamination also leads to change in oil characteristics, especially the viscosity, which is crucial for hydraulic system operation. As a result of large amounts of contaminants present in the working fluid, there is another problem, which is the accumulation of impurities in the gaps between working elements of hydraulic components that causes failures in the form of three types of blockages mechanical, physical-chemical, and thermal [46]. None of the reviewed papers provided the data on work fluids used by their systems. However, regardless of that, knowing that the clearances between movable and fixed work elements of 
these micro components are on the same order of magnitude as servo-hydraulic components, one can recommend ISO 16/14/11 (NAS 6) oil purity class for EHA/IEHA, according to manufacturers of servo-hydraulic components [47]. This purity class requires built-in filters, which separate the mentioned impurities of external or internal origin from the fluid, thus maintaining the nominal service life of hydraulic components and fluid, while maintaining flawless system operation. It is also important to know the location of filter within the system, due to possible problem with cavitations and insufficient oil in-flow which can occur when the filter is placed at the suction branch.

In comparison to conventional hydraulic systems, the advantage of IEHA device lies in the fact that it is fixed on an actuator (i.e., joint), minimizing the unnecessary losses in fluid energy transfer through pipe lines and hose lines. Moreover, IEHA devices prevent potential hose line entanglement hazard during robot operation, which could otherwise lead to reduced hose cross section, resulting in pressure bursts and hydraulic surges. The use of EHA/IEHA also increases system's dynamic ability and reduces the number of potential locations where the external oil leaks are likely to appear. The application of EHA/IEHA in conjunction with symmetrical hydraulic cylinders and a bidirectional hydraulic motor, eliminates the need for flow valve or distributor valves, since flow direction and pump capacity are regulated by the integrated pump micro-valve. Another advantage of this device is the compact assembly of miniaturized hydraulic components with small overall dimensions and a very good ability of integration. Reduced overall dimensions contribute to space efficiency and lower mass of the resulting system in which EHA/IEHA is installed.

There are some additional proposals which are not directly related to the EHA problem, but could be used to improve functionality of EHA or IEHA. Precup et al., proposed a new design method for 2-DOF controllers that can be used to improve control simplicity at a low cost, particularly in industrial applications [48]. The development of controllers which take into account the dynamics of the entire robotic system, including interaction effects with environment such as slipping, rolling, resistance, etc. $[49,50]$ must also be considered. Heron and Huges [51] developed a novel contaminant monitoring scheme to examine the cleanliness level of fluid in a hydraulic system, for in the presence of solid contaminants in the fluid, the friction between working elements of hydraulic components increases and the system operates in the critical zone. Crowther et al. [52] built a neural network model for a hydraulic actuation system, investigating the lack of supply pressure, internal leakage in the actuator, and dynamic friction load. Skormin and Apone [53] developed a failure prediction procedure, detecting and utilizing trends exhibited by parameter estimation. The investigated faults included the leakage of the hydraulic pumps. Gaspar et al., proposed an observerbased prediction control [54] which can be used to predict critical values in advance using a short time interval. Petra et al. successfully implemented the neural network solution [55] which provide good accuracy and reduce the high demand for computational resources. 


\section{Conclusions}

It is certain that the development of robotics is dependant upon the development of other related scientific and engineering areas. Hydraulics has definitely proven its worth in robotic applications, by yielding positive results in numerous laboratory experiments with EHA devices. These encouraging results further emphasize the need for constant research and development of hydraulic systems and components, and their modification to meet the requirements of various robotic applications.

As stated above, it can be noted that the EHA/IEHA devices have perspective in the field of robotics. As mentioned in Chapter 3, there are many ways to improve EHA/IEHA devices by implementing hardware and software solutions in order to: eliminate pulsations of pressure and flow, compensate positioning errors, simplify device installation, simplify equipment maintenance, improve accuracy, improve energy efficiency, etc.

Considering the application of hydraulics in robotics, it is certain that further research efforts shall be directed towards:

- Improving innovative design of hydraulic components used in the EHA and IEHA systems including miniaturization of hydraulic components and systems and developing ability to integrate hydraulic systems for robotic applications,

- Development of control systems for combined electro-hydraulic-mechanical actuators,

- Development of observer-based algorithms to predict critical parameters and improve time response of actuator,

- Development of procedures for the maintenance and preventive maintenance of miniature hydraulic systems,

- Development of power sources for electric motors in the form of miniature, large capacity batteries to enable long-term performance of EHA/IEHA systems in mobile applications.

\section{References}

[1] B. Batchelor, D. Hill, and H. Hodgson, "Automated Visual Inspection," 1985

[2] B. Davies, "A Review of Robotics in Surgery," Proceedings of the Institution of Mechanical Engineers, Part H: Journal of Engineering in Medicine, Vol. 214, pp. 129-140, 2000

[3] F. L. Lewis, C. T. Abdallah, and D. M. Dawson, Control of Robot Manipulators, Vol. 866: Macmillan Publishing Company New York, 1993 
[4] L. Briones, P. Bustamante, and M. A. Serna, "Wall-Climbing Robot for Inspection in Nuclear Power Plants," in Robotics and Automation, 1994. Proceedings, IEEE International Conference on, 1994, pp. 1409-1414

[5] B. Preising, T. Hsia, and B. Mittelstadt, "A Literature Review: Robots in Medicine," Engineering in Medicine and Biology Magazine, IEEE, Vol. 10, pp. 13-22, 1991

[6] A. Iborra, J. A. Pastor, B. Alvarez, C. Fernandez, and J. M. F. Merono, "Robots in Radioactive Environments," Robotics \& Automation Magazine, IEEE, Vol. 10, pp. 12-22, 2003

[7] A. Esser and H.-C. Skudelny, "A New Approach to Power Supplies for Robots," Industry Applications, IEEE Transactions on, Vol. 27, pp. 872875,1991

[8] K. Amundson, J. Raade, N. Harding, and H. Kazerooni, "Hybrid HydraulicElectric Power Unit for Field and Service Robots," in Intelligent Robots and Systems, (IROS 2005) 2005 IEEE/RSJ International Conference on, 2005, pp. 3453-3458

[9] E. P. Gels, "Electroactive Polymer (EAP) Actuators as Artificial Muscles: Reality, Potential, and Challenges," 2004

[10] T. Fukuda, H. Hosokai, H. Ohyama, H. Hashimoto, and F. Arai, "Giant Magnetostrictive Alloy (GMA) Applications to Micro Mobile Robot as a Micro Actuator without Power Supply Cables," in Micro Electro Mechanical Systems, 1991, MEMS'91, Proceedings. An Investigation of Micro Structures, Sensors, Actuators, Machines and Robots. IEEE, pp. 210-215

[11] H. Prahlad, R. Pelrine, S. Stanford, J. Marlow, and R. Kornbluh, "Electroadhesive Robots-Wall Climbing Robots Enabled by a Novel, Robust, and Electrically Controllable Adhesion Technology," in Robotics and Automation, ICRA 2008, IEEE International Conference on, pp. 30283033 .

[12] N. G. Tsagarakis, M. Laffranchi, B. Vanderborght, and D. G. Caldwell, "A Compact Soft Actuator Unit for Small Scale Human Friendly Robots," in Robotics and Automation, ICRA'09, IEEE International Conference on, 2009, pp. 4356-4362

[13] S. Murata, E. Yoshida, A. Kamimura, H. Kurokawa, K. Tomita, and S. Kokaji, "M-TRAN: Self-Reconfigurable Modular Robotic System," Mechatronics, IEEE/ASME Transactions on, Vol. 7, pp. 431-441, 2002

[14] B. N. Ashton, "Self-contained Power Actuator," ed: Google Patents, 1954

[15] S. Frischemeier, "Electrohydrostatic Actuators for Aircraft Primary Flight Control-Types, Modelling and Evaluation," in Proceedings of the Fifth Scandinavian International Conference on Fluid Power, 1997, pp. 28-30 
[16] K. Waldron and R. McGhee, "The Adaptive Suspension Vehicle," Control Systems Magazine, IEEE, Vol. 6, pp. 7-12, 1986

[17] S.-M. Song and K. J. Waldron, Machines that Walk: the Adaptive Suspension Vehicle: MIT press, 1988

[18] K. J. Waldron, V. J. Vohnout, A. Pery, and R. B. McGhee, "Configuration Design of the Adaptive Suspension Vehicle," The International Journal of Robotics Research, Vol. 3, pp. 37-48, 1984

[19] J. Bobrow and J. Desai, "Modeling and Analysis of a High-Torque, Hydrostatic Actuator for Robotic Applications," in Experimental Robotics I, 1990, pp. 215-228

[20] L. Walha, T. Fakhfakh, and M. Haddar, "Backlash Effect on Dynamic Analysis of a Two-Stage Spur Gear System," Journal of Failure Analysis and Prevention, Vol. 6, pp. 60-68, 2006

[21] V. Pastrakuljic, "Design and Modeling of a New Electro-Hydraulic Actuator," MSc, Department of Mechanical Engineering, University of Toronto, Toronto, Canada, 1995

[22] S. Habibi and A. Goldenberg, "Design of a New High Performance Electrohydraulic Actuator," in Advanced Intelligent Mechatronics, 1999. Proceedings. 1999 IEEE/ASME International Conference on, pp. 227-232

[23] S. Habibi, V. Pastrakujic, and A. Goldenberg, "Model Identification of a High Performance Hydrostatic Actuation System," American Society of Mechanical Engineers, The Fluid Power and Systems Technology Division (Publication) FPST, Vol. 7, pp. 113-119, 2000

[24] S. Alfayad, F. Ouezdou, F. Namoun, and G. Cheng, "Lightweight High Performance Integrated Actuator for Humanoid Robotic Applications: Modeling, Design \& Realization," in Robotics and Automation, 2009. ICRA'09. IEEE International Conference on, 2009, pp. 562-567

[25] S. Alfayad, F. B. Ouezdou, F. Namoun, and G. Gheng, "High Performance Integrated Electro-Hydraulic Actuator for Robotics-Part I: Principle, Prototype Design and First Experiments," Sensors and Actuators A: Physical, Vol. 169, pp. 115-123, 2011

[26] S. Alfayad, F. B. Ouezdou, F. Namoun, and G. Gheng, "High Performance Integrated Electro-Hydraulic Actuator for Robotics. Part II: Theoretical Modelling, Simulation, Control \& Comparison with Real Measurements," Sensors and Actuators A: Physical, Vol. 169, pp. 124-132, 2011

[27] G. Cheng, S.-H. Hyon, J. Morimoto, A. Ude, J. G. Hale, G. Colvin, W. Scroggin, and S. C. Jacobsen, "CB: A Humanoid Research Platform for Exploring Neuroscience," Advanced Robotics, Vol. 21, pp. 1097-1114, 2007 
[28] M. Raibert, K. Blankespoor, G. Nelson, and R. Playter, "Bigdog, the Rough-Terrain Quadruped Robot," in Proceedings of the $17^{\text {th }}$ World Congress, 2008, pp. 10823-10825

[29] A. Kargov, T. Asfour, C. Pylatiuk, R. Oberle, H. Klosek, S. Schulz, K. Regenstein, G. Bretthauer, and R. Dillmann, "Development of an Anthropomorphic Hand for a Mobile Assistive Robot," in Rehabilitation Robotics, ICORR 2005, $9^{\text {th }}$ International Conference on, 2005, pp. 182-186

[30] A. Kargov, T. Werner, C. Pylatiuk, and S. Schulz, "Development of a Miniaturised Hydraulic Actuation System for Artificial Hands," Sensors and Actuators A: Physical, Vol. 141, pp. 548-557, 2008

[31] H. Kaminaga, J. Ono, Y. Shimoyama, T. Amari, Y. Katayama, and Y. Nakamura, "Anthropomorphic Robot Hand with Hydrostatic Cluster Actuator and Detachable Passive Wire Mechanism," in Humanoid Robots, Humanoids 2009, $9^{\text {th }}$ IEEE-RAS International Conference on, 2009, pp. 1-6

[32] H. Kaminaga, J. Ono, Y. Nakashima, and Y. Nakamura, "Development of Backdrivable Hydraulic Joint Mechanism for Knee Joint of Humanoid Robots," in Robotics and Automation, 2009, ICRA'09, IEEE International Conference on, pp. 1577-1582

[33] P. Galambos, "Vibrotactile Feedback for Haptics and Telemanipulation: Survey, Concept and Experiment," Acta Polytechnica Hungarica, Vol. 9, pp. 41-65, 2012

[34] R. Abduli and P. Cener, Electrohydraulic Servo Systems. Belgrade: Military Press Center, 1986

[35] H. Kaminaga, T. Amari, Y. Niwa, and Y. Nakamura, "Electro-Hydrostatic Actuators with Series Dissipative Property and Their Application to Power Assist Devices," in Biomedical Robotics and Biomechatronics (BioRob), $20103^{\text {rd }}$ IEEE RAS and EMBS International Conference on, pp. 76-81

[36] H. Kaminaga, H. Tanaka, and Y. Nakamura, "Mechanism and Control of Knee Power Augmenting Device with Backdrivable Electro-Hydrostatic Actuator," in Proc. of $13^{\text {th }}$ World Congress in Mechanism and Machine Science, 2011, p. 534

[37] H. Kaminaga, T. Amari, Y. Niwa, and Y. Nakamura, "Development of Knee Power Assist using Backdrivable Electro-Hydrostatic Actuator," in Intelligent Robots and Systems (IROS), 2010 IEEE/RSJ International Conference on, 2010, pp. 5517-5524

[38] H. Kaminaga, H. Tanaka, K. Yasuda, and Y. Nakamura, "Screw Pump for Electro-Hydrostatic Actuator that Enhances Backdrivability," in Humanoid Robots (Humanoids), $201111^{\text {th }}$ IEEE-RAS International Conference on, pp. 434-439 
[39] H. Kaminaga, H. Tanaka, K. Yasuda, and Y. Nakamura, "Viscous Pump for Highly Backdrivable Electro-Hydrostatic Actuator," in Robotics and Automation (ICRA), 2012 IEEE International Conference on, pp. 37513756

[40] Y. A. Chinniah, "Fault Detection in the Electrohydraulic Actuator using Extended Kalman Filter," PhD, Department of Mechanical Engineering, University of Saskatchewan, Saskatoon, Canada, 2004

[41] E. B. Sampson, "Fuzzy Control of the Electrohydraulic Actuator," PhD, Department of Mechanical Engineering, University of Saskatchewan, Saskatoon, Canada, 2005

[42] Y. Lin, "Controller Design for Hydraulic Position Control Systems," PhD, Department of Mechanical Engineering, University of Saskatchewan, Saskatoon, Canada, 2011

[43] M. Ijas, "Damping of Low Frequency Pressure Oscillation," Tampereen teknillinen yliopisto. Julkaisu-Tampere University of Technology. Publication; 656, 2007

[44] W. Becke, J. Esser, H. Bublitz, U. Kooths, and O. Trecker, "Adaptive Hydropneumatic Pulsation Damper," ed: Google Patents, 1998

[45] S. Washio, S. Takahashi, M. K., and S. Yamaguchi, "Oil Hydraulic Pulsation Filters of Helmholtz Resonator Type," Hydraulics \& Pneumatics, Vol. 24, pp. 729-735, 1993

[46] M. Jocanović, "Determination and Researching of Calculation Model for Solid Particle Flow with Oil Mass through Gaps, Depending on Constructional and Working Parameters of Hydraulic Components," PhD Doctoral, University of Novi Sad, Novi Sad, 2010

[47] M. Jocanović and V. Karanović, "Appendix to Researching Criteria for Defining Needful Grade of Clearness of Hydraulics Fluids in Accordance with Hydraulics Components and System Requirements," in $8^{\text {th }}$ International Conference on Accomplishments in Electrical, Mechanical and Informatic Engineering DEMI, Banja Luka, 2007, pp. 869-876

[48] R.-E. Precup, S. Preitl, E. M. Petriu, J. K. Tar, M. L. Tomescu, and C. Pozna, "Generic Two-Degree-of-Freedom Linear and Fuzzy Controllers for Integral Processes," Journal of the Franklin Institute, Vol. 346, pp. 9801003, 2009

[49] A. Rodic and Gy. Mester, "Sensor-based Navigation and Integrated Control of Ambient Intelligent Wheeled Robots with Tire-Ground Interaction Uncertainties," Acta Polytechnica Hungarica, Vol. 10, 2013

[50] A. Widyotriatmo, A. K. Pamosoaji, and K.-S. Hong, "Control Architecture of an Autonomous Material Handling Vehicle," International Journal of Artificial Intelligence, Vol. 10, pp. 139-153, 2013 
[51] R. Heron and M. Huges, "A Contaminant Monitor for Fluid Power Applications," in International Conference on Condition Monitoring, Brighton, UK, 1986, pp. 57-71

[52] W. Crowther, K. Edge, C. Burrows, R. Atkinson, and D. Woollons, "Fault Diagnosis of a Hydraulic Actuator Circuit using Neural Networks-an Output Vector Space Classification Approach," Proceedings of the Institution of Mechanical Engineers, Part I: Journal of Systems and Control Engineering, Vol. 212, pp. 57-68, 1998

[53] V. A. Skormin and J. Apone, "On-Line Diagnostics of a Variable Displacement Pump of a Flight Actuation System," in Aerospace and Electronics Conference, NAECON 1995, Proceedings of the IEEE 1995 National, pp. 503-510

[54] P. Gaspar, I. Szaszi, and J. Bokor, "The Design of a Combined Control Structure to Prevent the Rollover of Heavy Vehicles," European Journal of Control, Vol. 10, pp. 148-162, 2004

[55] M. I. Petra and L. C. DeSilva, "Implementation of Folding Architecture Neural Networks into an FPGA for an Optimized Inverse Kinematics Solution of a Six-Legged Robot," International Journal of Artificial Intelligence, Vol. 10, pp. 123-138, 2013 